\title{
Implementasi Mikrokontroler pada Sistem Kontrol Peralatan Listrik dan Monitoring Rumah Berbasis Website
}

\author{
Harry Luanda Sadewa ${ }^{1}$ Herry Sujaini ${ }^{2}$ Rudy Dwi Nyoto ${ }^{3}$ \\ ${ }^{1}$ Program Studi Informatika Universitas Tanjungpura \\ e-mail: harry.luanda@gmail.com, herry_sujaini@yahoo.com,rudy_dn@yahoo.com
}

\begin{abstract}
Abstrak-Meningkatnya taraf hidup masyarakat dimana ditandai dengan aktifitas dan pergerakan masyarakatnya yang selalu meningkat tiap tahunnya. Selama ini masyarakat cenderung mengontrol listrik secara manual menggunakan saklar yang harus dioperasikan dengan bantuan manusia dimana pengendalian tersebut terbentur oleh jarak. Salah satu solusi agar suatu perangkat dapat dikontrol secara maksimal dan cakupan jarak kontrolnya semakin luas adalah menggunakan mikontroler yang terhubung dengan internet sehingga bisa diakses dari jarak jauh.Didukung oleh sistem yang berbasis website membuat sistem dapat menampung pengguna dalam jumlah banyak atau biasa disebut multi pengguna. Untuk memaksimalkan kerja dari sistem sendiri digunakan Basis Data sebagai penyimpanan log informasi baik data monitoring, pengaturan perangkat keras, maupun status terakhir dari relay.Pada simulasi yang dilakukan pada jaringan lokal, sistem yang dibangun sudah mampu melakukan fungsi kontrol dan monitoring dengan maksimal relay yang mampu diakomodir adalah 8 buah dan sensor sebanyak 4 buah. Kemudian pada simulasi yang dilakukan terhadap dua buah perangkat arduino, sistem yang dibangun sudah mendukung multi pengguna. Meski untuk fungsi kontrol peralatan listrik tidak ada masalah, penggunaan beberapa sensor masih menjadi kendala karena diperlukannya library tambahan agar dapat bekerja dengan baik pada sistem.
\end{abstract}

Kata Kunci-Kontrol Peralatan Listrik, Monitoring Rumah Mikrokontroler, Sensor, Relay

\section{PENDAHULUAN}

$\mathrm{D}^{\mathrm{i}}$ kota-kota besar aktifitas masyarakat sangatlah padat, dimana masyarakat sibuk akan pekerjaannya yang memakan waktu dari pagi hingga sore bahkan hingga malam hari. Akibatnya membuat beberapa aktifitas rumah tangga seperti menghidupkan lampu pada malam hari menjadi terbengkalai. Selama ini masyarakat cenderung mengontrol lisrtik secara manual menggunakan saklar yang harus dioperasikan dengan bantuan manusia dimana pengendalian tersebut terbentur oleh jarak. Agar suatu perangkat dapat dikontrol secara maksimal dan cakupan jarak kontrolnya semakin luas salah satu solusinya adalah menggunakan mikontroler yang terhubung dengan internet sehingga bisa diakses dari jarak jauh. Selain itu diperlukan monitoring keadaan dengan bantuan sensor agar kinerja dari sistem ini lebih maksimal, contohnya untuk memutus arus listrik pada lampu diperlukan sensor cahaya untuk memberikan gambaran apakah sudah tepat dalam menghidupkan atau mematikan lampu.

Beberapa penelitian sebelumnya yang membahas sistem kontrol salah satu diantaranya adalah Arya Lazuardiyang mencoba mengontrol switch breaker melalui sebuah SMS yang telah diterjemahkan menjadi command control. Selain sebagai media kontrol, SMS juga dapat memberikan laporan dari feed back device yang dikendalikan oleh mikrokontroller sehingga dapat mengetahui status proses kontrol suatu switch breakersudah berjalan dengan benar atau tidak [1]. Kemudian peneliti lainnya seperti Muhammad Ichwan, Milda Gustiana, dan M. Iqbal Ar Rasyid dengan menggunakan Platform Android, peneliti membangun sebuah prototype sistem pengendalian peralatan listrik jarak jauh [2].

Mengimplementsikan mikrokontroler pada sebuah sistem kontrol listrik dan monitoring rumah yang dibangun dengan basis website dapat berguna sebagai sebuah solusi alternatif baru untuk pengendalian jarak jauh. Sistem yang dibangun dengan basis website dapat memudahkan pengguna mengontrol listrik rumahnya dari perangkat manapun baik perangkat mobile maupun dekstop secara realtime. Selain itu dengan mengimplementasikan sistem dengan basis website, jumlah pengguna yang dapat diakomodir lebih banyak sehingga membuat perawatan terhadap sistem cukup dilakukan oleh satu pihak yaitu pihak pengembang sistem.

\section{MIKROKONTROLER}

Menurut Iswanto mikrokontroler adalah suatu rangkaian terintegerasi (IC) yang bekerja untuk aplikasi pengendalian. Meskipun mempunyai bentuk lebih kecil dari komputer pribadi dan mainframe, mikrokontroler dibangun dengan elemen-elemen yang sama [3]. Mikrokontroler adalah alat yang mengerjakan instruksi-instruksi yang diberikan, artinya bagian utama dari suatu sistem otomatis/terkomputerisasi adalah program didalamnya dibuat oleh programmer. Program menginstruksikan mikrokontroler untuk melakukan jalinanyang panjang dari aksi-aksi sederhana untuk melakukan tugas yang lebih kompleks sesuai keinginan programmer.

\section{A. Arduino}

Arduino adalah pengendali mikro single-board yang bersifat open-source, yang dirancang untuk memudahkan penggunaan elektronik dalam berbagai bidang. Pada bagian hardware 
(perangkat keras) memiliki prosesor Atmel AVR dan bagian software (perangkat lunak) memiliki bahasa pemrograman sendiri. Mikrokontroler single-board yang bersifat open source hardware dikembangkan untuk arsitektur mikrokontroler AVR 8 bit dan ARM 32 bit.

Arduino Leonardo merupakan sebuah papan mikrokontroler yang berbasis Atmega32u4 diperlihatkan pada Gambar 1. Arduino Leonardo memiliki 20 input/output pin dimana 7 diantaranya dapat digunakan sebagai keluaran PWM (Pulse Width Modulation) yang digunakan sebagai pengontrol suatu objek dengan menggunakan impulse listrik, dan 12 pin sisanya digunakan sebagai masukan analog. Arduino Leonardo juga dilengkapi dengan sebuah $16 \mathrm{MHz}$ crystal oscillator, sebuah koneksi micro USB, sebuah catu daya, sebuah ICSP header, dan sebuah tombol reset. Arduino Leonardo sudah memiliki semua yang dibutuhkan untuk mendukung mikrokontroler seperti mudah untuk menghubungkannya ke komputer melalui kabel USB dan catu daya yang sederhana menggunakan tenaga dari USB ataupun dengan batrai $12 \mathrm{~V}$.

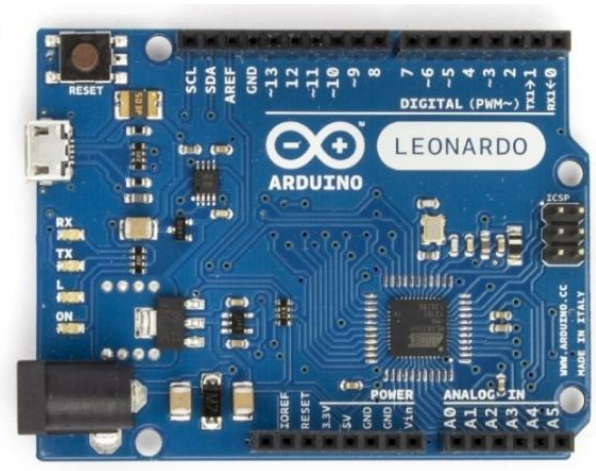

Gambar 1. Arduino Leonardo

Sumber www.arduino.cc

\section{B. Ethernet Shield}

Arduino Ethernet Shield seperti Gambar 2 merupakan komponen tambahan yang berfungsi menghubungkan papan Arduino ke Internet secara langsung. Arduino Ethernet Shield dapat berfungsi sebagai web server yang nantinya bisa digunakan untuk mengontrol atau memonitoring sebuah mikrokontroler. Alat ini terhubung dengan internet melalui kabel RJ45 yang bisa langsung terkoneksi dengan internet maupun melalui router terlebih dahulu. Arduino Ethernet Shield sudah mendukung IP static maupun IP dinamis (DHCP).

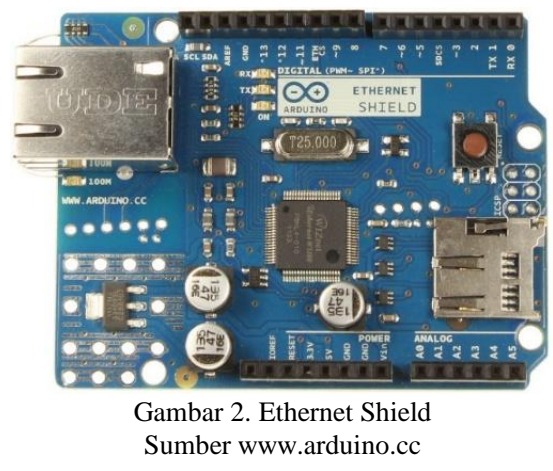

\section{PERANCANGAN DAN IMPLEMENTASI}

\section{A. Metodologi Penelitian}

Di dalam penelitian ini dilakukan dengan beberapa tahapan, dimulai dengan desain arsitektur, lalu pembangunan perangkat mikrokontroler, desain aplikasi, implementasi, dan terakhir pengujian sistem yang dibangun. Seperti di gambarkan pada diagram alir pada gambar 1 .

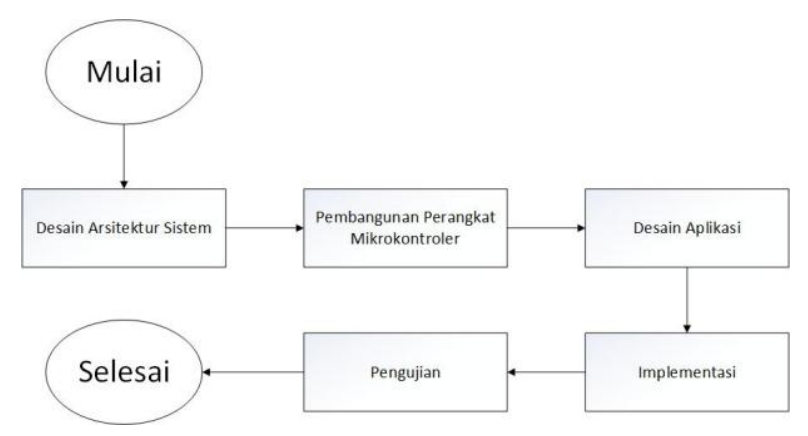

Gambar 1. Metodologi Penelitian

\section{B. Arsitektur Sistem}

Arsitektur sistem merupakan gambaran garis besar cara kerja sistem yang digambarkan melalui model-model yang saling berhubungan. Pada gambar 2 digambarkan arsitektur sistem yang dibuat.

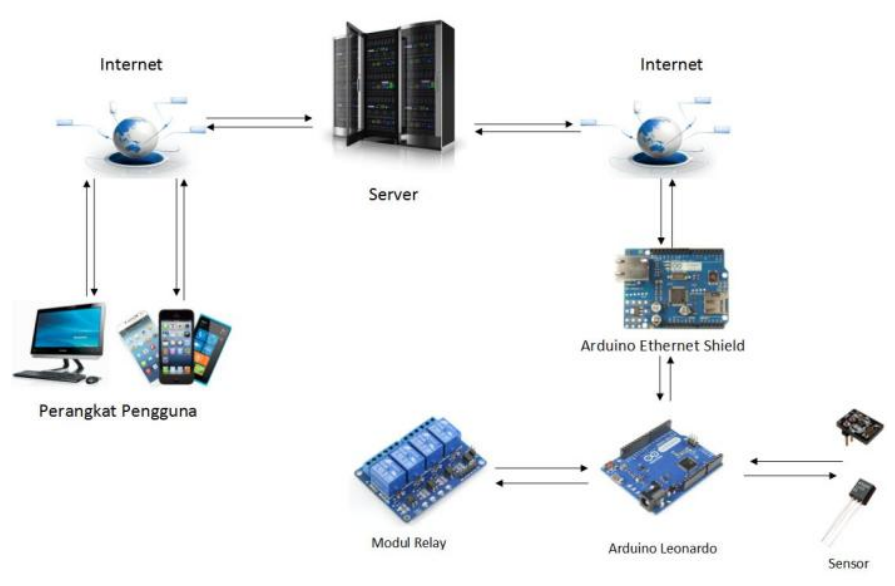

Gambar 2. Arsitektur Sistem

\section{Use Case Diagram}

Use case adalah abstraksi dari interaksi antara sistem dan aktor. Use case bekerja dengan cara mendeskripsikan tipe interaksi antara pengguna sebuah sistem dengan sistemnya sendiri melalui sebuah cerita bagaimana sebuah sistem dipakai. Pada gambar 3 yang merupakan diagram use case aktor dapat melakukan beberapa perilaku diantaranya melakukan kontrol listrik, memonitoring rumah, melakukan pengaturan terhadap IP target, sensor dan relay, serta dapat menampilkan bantuan dan deskripsi aplikasi. 


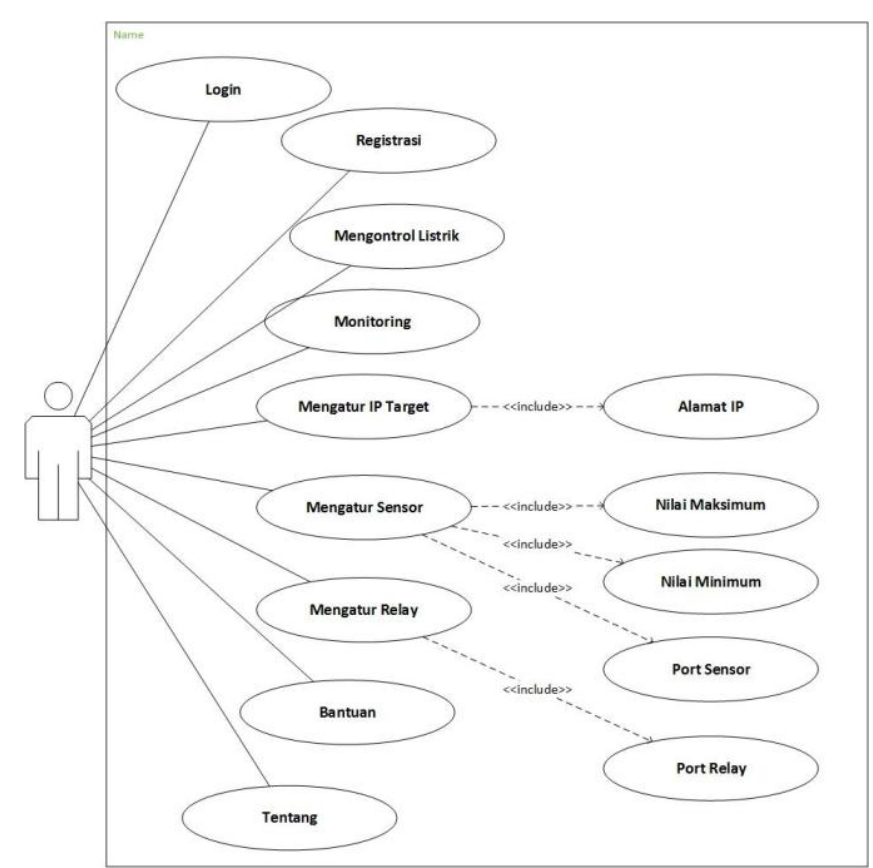

Gambar 3. Use Case Diagram

\section{Activity Diagram}

Activity diagram merupakan diagram yang menggambarkan berbagai alir aktivitas dalam sistem yang sedang dirancang, bagaimana masing-masing alir berawal, decision yang mungkin terjadi, dan bagaimana mereka berakhir. Dalam activity diagram pada gambar 4 menunjukkan terlihat alur pengguna ketika menggunakan aplikasi tersebut.

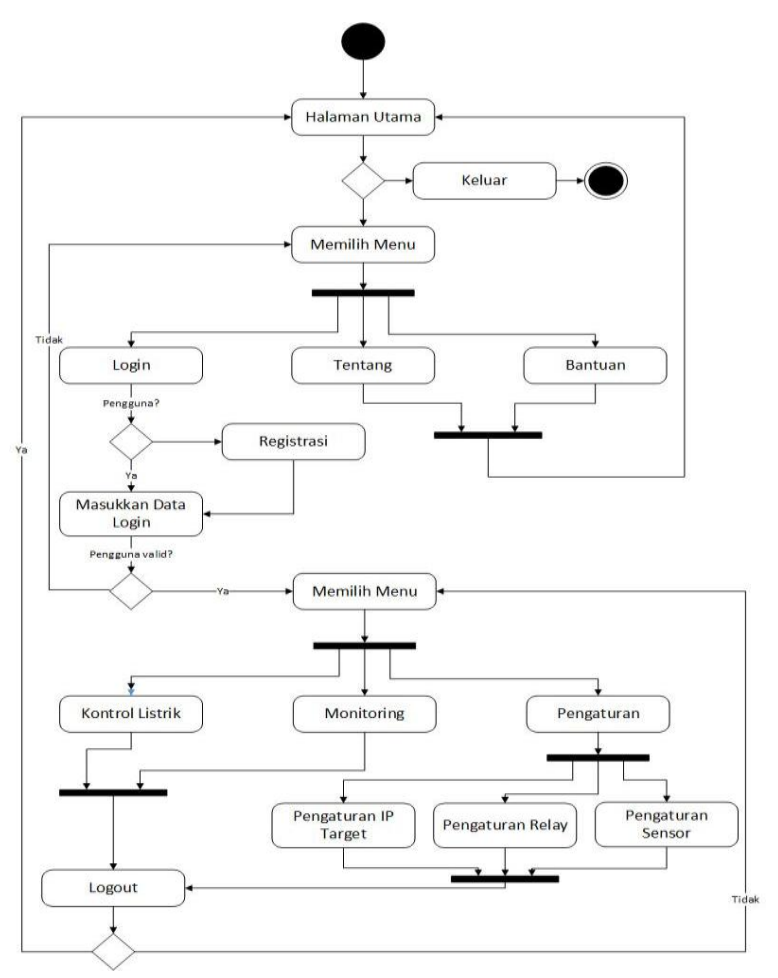

Gambar 4. Activity Diagram

\section{E. Perancangan Struktur Antarmuka}

Sistem kontrol listrik dan monitoring rumah adalah sebuah sistem berbasis website yang dirancang memiliki beberapa fungsi dan fitur yang disesuaikan dengan kebutuhan sistem. Struktur antarmuka aplikasi yang dibangun dapat dilihat pada Gambar 5 berikut:

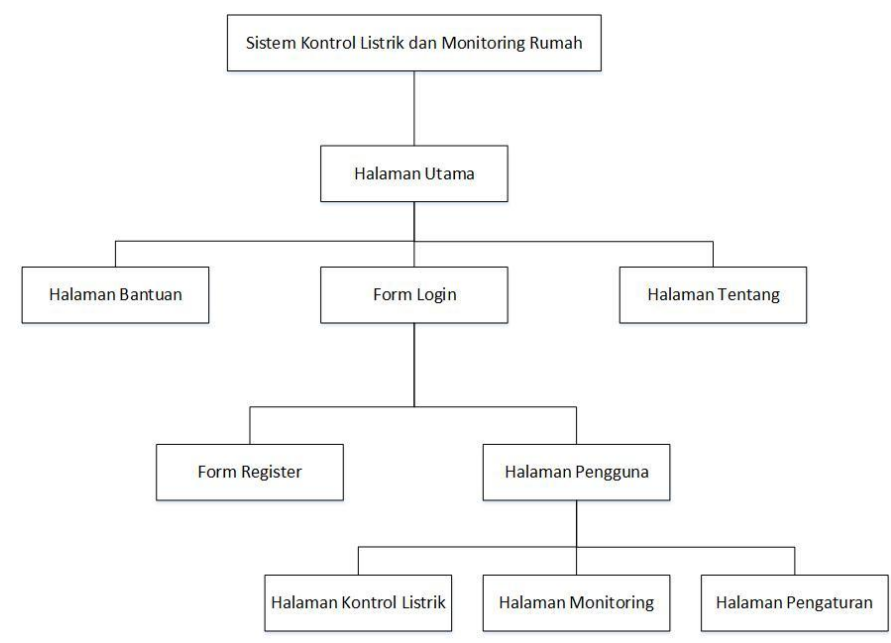

Gambar 5. Struktur Antarmuka

\section{F. Perangkat Keras Arduino}

Gambar berikut merupakan hasil rancangan prototype alat yang digunakan pada sistem kontrol listrik dan monitoring rumah.

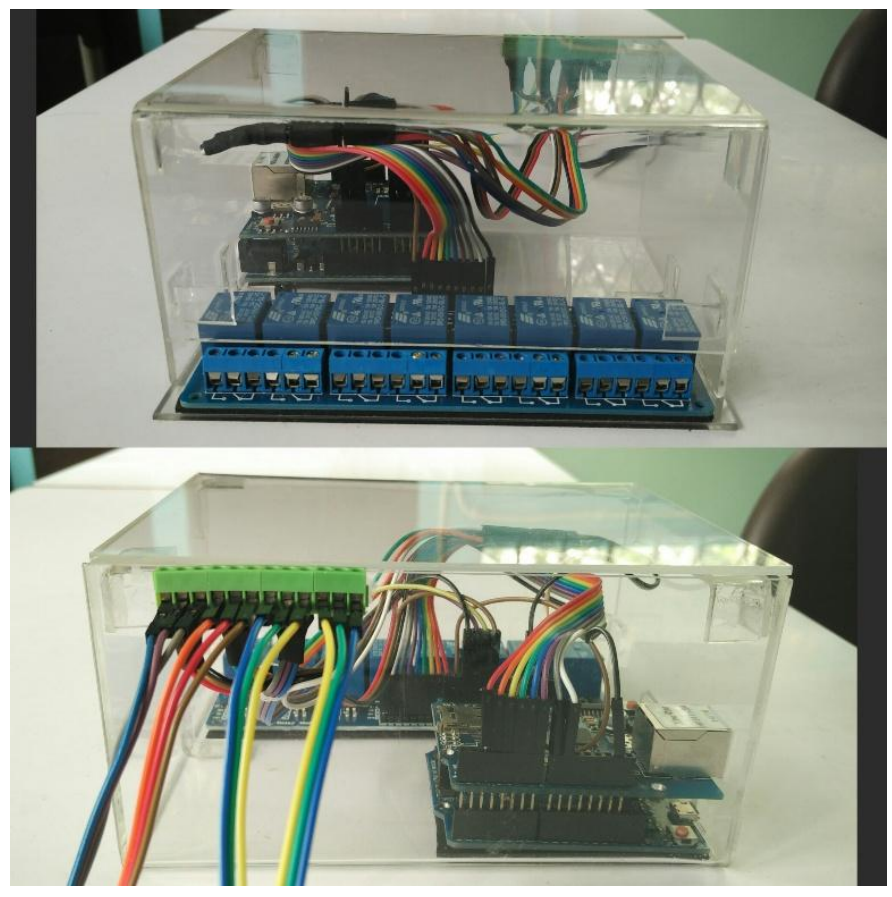

Gambar 6. Perangkat Keras 


\section{G. Antarmuka Aplikasi}

Antarmuka aplikasi merupakan tampilan yang digunakan oleh pengguna ketika menggunakan sistem. Antarmuka aplikasi disini berfungsi untuk memberikan perintah pada perangkat, menerima data monitoring, dan pengaturan dasar pada aplikasi.

Antarmuka halaman kontrol merupakan halaman pertama yang tampil ketika pengguna selesai melakukan login dan sudah diverifikasi oleh sistem. Halaman kontrol pada Gambar 7 sendiri berfungsi untuk memberikan instruksi kepada sistem untuk menghidupkan atau mematikan listrik, yang nantinya instruksi tersebut akan diubah menjadi aksi oleh sistem.

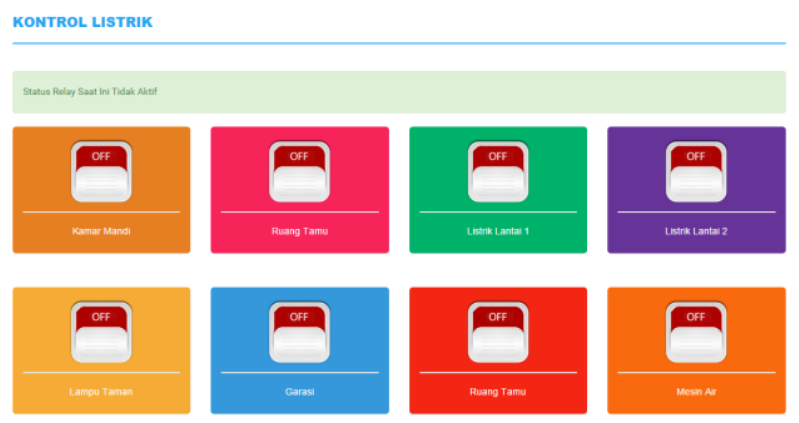

Gambar 7. Antarmuka Halaman Kontrol Peralatan Listrik

Antarmuka halaman monitoring merupakan halaman yang dapat diakses pengguna untuk menampilkan monitoring sensor yang telah diinstalasi oleh pengguna. Halaman monitoring pada Gambar 8 berisikan besaran angka hasil monitoring yang sebelumnya telah diproses oleh sistem dalam bentuk persentase.

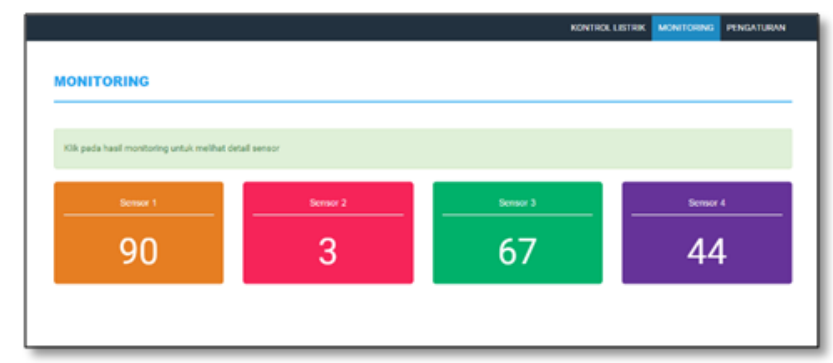

Gambar 8. Antarmuka Halaman Monitoring

Halaman grafik monitoring pada Gambar 9 adalah tindak lanjut dari halaman monitoring yang berisi detail dari monitoring yang dipilih. Grafik yang ditampilkan berupa 100 data terakhir yang dikirimkan oleh sistem dan diolah menjadi grafik.

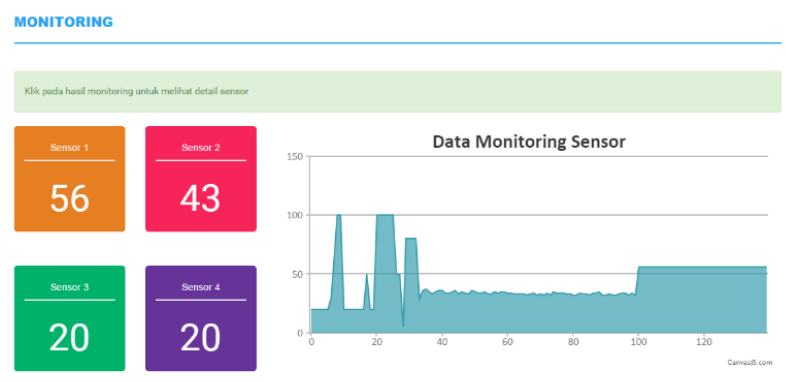

Gambar 9. Antarmuka Halaman Grafik Monitoring

Antarmuka halaman pengaturan kontrol peralatan listrik pada gambar 10 merupakan halaman yang berfungsi untuk mengubah pengaturan fungi kontrol pada aplikasi. Pengguna dapat mengatur fungsi relay tersebut dan mematikan atau menghidupkannya.

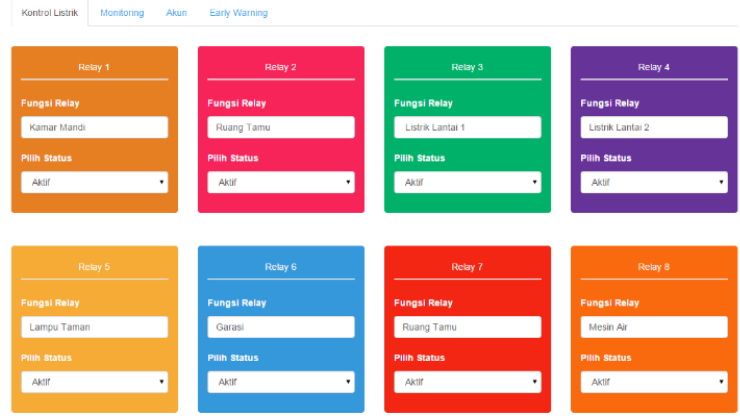

Gambar 10. Halaman Pengaturan Kontrol Peralatan Listrik

Antar muka halaman pengaturan sensor berisikan pengaturan yang berfungsi diantaranya memberikan pengaturan informasi sensor, kalibrasi sensor, dan status sensor itu sendiri. Pada halaman pengaturan sensor pada Gambar 11 Pengguna dapat melakukan kalibrasi sensor jika diperlukan,serta pengguna dapat menghidupkan atau mematikan fungsi monitoring pada sensor tersebut.
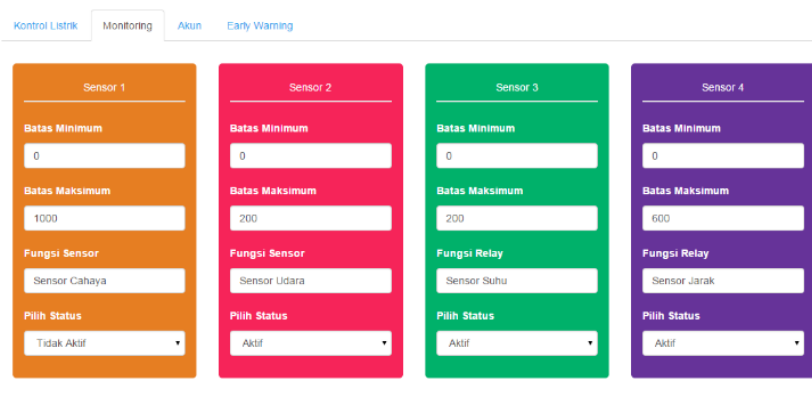

Gambar 11. Antarmuka Halaman Pengaturan Monitoring

Antar muka halaman pengaturan akun pada Gambar 12 berisikan informasi mengenai akun pengguna. Pengguna sendiri dapat mengubah beberapa informasi tersebut diantaranya email, nomor handphone, serta alamat IP Target. 
PENGaturan

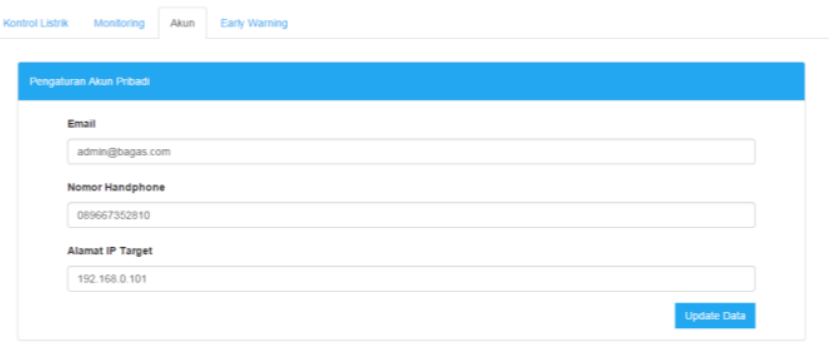

Gambar 12. Antarmuka Halaman Pengaturan Akun

\section{PENGUJIAN DAN ANALISIS}

\section{A. Pengujian Dengan Metode Blackbox Perangkat Lunak}

Pengujian dengan metode black box pada perangkat lunak dilakukan untuk menguji kesesuaian logika yang dibuat dengan hasil yang ditampilkan pada perangkat keras. Pengujian dilakukan dengan memberikan input berupa perintah "On" dan "Off" pada pada aplikasi, lalu melakukan pengamatan terhadap perangkat keras apakah bekerja sesuai dengan perintah yang diberikan.

Tabel 1

Tabel Pengujian Dengan Metode Black Box Perangkat Lunak

\begin{tabular}{|l|l|l|}
\hline Jenis Pengujian & $\begin{array}{l}\text { Hasil Yang } \\
\text { Diharapkan }\end{array}$ & Hasil \\
\hline $\begin{array}{l}\text { Mengirim perintah } \\
\text { "On" pada relay 1 }\end{array}$ & Relay 1 Hidup & Berhasil \\
\hline $\begin{array}{l}\text { Mengirim perintah } \\
\text { "Off" pada relay 1 }\end{array}$ & Relay 1 Mati & Berhasil \\
\hline $\begin{array}{l}\text { Mengirim perintah } \\
\text { "On" pada relay 2 }\end{array}$ & Relay 2 Hidup & Berhasil \\
\hline $\begin{array}{l}\text { Mengirim perintah } \\
\text { "Off” pada relay 2 }\end{array}$ & Relay 2 Mati & Berhasil \\
\hline $\begin{array}{l}\text { Mengirim perintah } \\
\text { "On" pada relay 3 }\end{array}$ & Relay 3 Hidup & Berhasil \\
\hline $\begin{array}{l}\text { Mengirim perintah } \\
\text { "Off" pada relay 3 } \\
\text { "Off" pada relay 4 pada relay 4 }\end{array}$ & Relay 3 Mati & Berhasil \\
\hline Mengirim perintah & Relay 5 Hidup & Berhasil \\
\hline
\end{tabular}

\begin{tabular}{|l|l|l|}
\hline "On" pada relay 5 & & \\
\hline $\begin{array}{l}\text { Mengirim perintah } \\
\text { "Off" pada relay 5 }\end{array}$ & Relay 5 Mati & Berhasil \\
\hline $\begin{array}{l}\text { Mengirim perintah } \\
\text { "On" pada relay 6 }\end{array}$ & Relay 6 Hidup & Berhasil \\
\hline $\begin{array}{l}\text { Mengirim perintah } \\
\text { "Off" pada relay 6 }\end{array}$ & Relay 6 Mati & Berhasil \\
\hline $\begin{array}{l}\text { Mengirim perintah } \\
\text { "On" pada relay 7 }\end{array}$ & Relay 7 Hidup & Berhasil \\
\hline $\begin{array}{l}\text { Mengirim perintah } \\
\text { "Off" pada relay 7 }\end{array}$ & Relay 7 Mati & Berhasil \\
\hline $\begin{array}{l}\text { Mengirim perintah } \\
\text { "On" pada relay 8 }\end{array}$ & Relay 8 Hidup & Berhasil \\
\hline $\begin{array}{l}\text { Mengirim perintah } \\
\text { "Off" pada relay 8 }\end{array}$ & Relay 8 Mati & Berhasil \\
\hline
\end{tabular}

Berdasarkan Tabel 1 telihat bahwa hasil pengujian memberikan hasil yang sesuai dengan yang diharapkan. Semua perintah yang diberikan pada alat mikrokontroler dapat berjalan dengan baik.

Tabel 2

Tabel Pengujian Kemampuan Perangkat Membaca Perintah Secara Beruntun

\begin{tabular}{|l|l|l|}
\hline Jenis Pengujian & $\begin{array}{l}\text { Hasil Yang } \\
\text { Diharapkan }\end{array}$ & Hasil \\
\hline $\begin{array}{l}\text { Memberikan perintah } \\
\text { pada relay secara } \\
\text { beruntun sebanyak 5 } \\
\text { kali }\end{array}$ & $\begin{array}{l}\text { Perangkat dapat } \\
\text { memberikan output } \\
\text { sesuai perintah } \\
\text { terakhir yang } \\
\text { dikirimkan }\end{array}$ & Berhasil \\
\hline $\begin{array}{l}\text { Memberikan perintah } \\
\text { pada relay secara } \\
\text { beruntun sebanyak 10 } \\
\text { kali }\end{array}$ & $\begin{array}{l}\text { Perangkat dapat } \\
\text { memberikan output } \\
\text { sesuai perintah } \\
\text { terakhir yang } \\
\text { dikirimkan }\end{array}$ & Tidak Berhasil \\
\hline $\begin{array}{l}\text { Memberikan perintah } \\
\text { pada relay secara } \\
\text { beruntun sebanyak 15 } \\
\text { kali }\end{array}$ & $\begin{array}{l}\text { Perangkat dapat } \\
\text { memberikan output } \\
\text { sesuai perintah } \\
\text { terakhir yang } \\
\text { dikirimkan }\end{array}$ & Tidak Berhasil \\
\hline
\end{tabular}




\begin{tabular}{|l|l|l|}
\hline $\begin{array}{l}\text { Memberikan perintah } \\
\text { pada relay secara }\end{array}$ & $\begin{array}{l}\text { Perangkat dapat } \\
\text { memberikan output }\end{array}$ & Tidak Berhasil \\
kali & sesuai perintah \\
terakhir yang & dikirimkan & \\
\hline Memberikan perintah & Perangkat dapat & Tidak Berhasil \\
pada relay secara & memberikan output & \\
beruntun sebanyak 30 & sesuai perintah & \\
kali & terakhir yang & \\
& dikirimkan & \\
\hline
\end{tabular}

Berdasarkan hasil pengujian yang tertera pada Tabel 2 terlihat bahwa pengujian yang dilakukan menunjukkan perangkat hanya mampu mengakomodir perintah secara beruntun sebanyak 5 kali. Hal ini terjadi karena delay yang terjadi ketika proses pengiriman perintah sehingga membuat perangkat tidak bisa membaca perintah tersebut secara maksimal.

\section{B. Pengujian Kompatibilitas Sensor}

Langkah berikutnya adalah melakukan pengujian kompatibilitas terhadap sensor, hal ini dilakukan untuk mengetahui kemampuan sistem dalam membaca sensor. Sensor yang dipasang dikalibrasi dengan memasukkan nilai keluaran minimum dan maksimum yang diberikan oleh sensor.

Tabel 3

Tabel Pengujian Kompatibilitas Sensor

\begin{tabular}{|l|l|l|l|}
\hline Merk dan Tipe & Jenis Sensor & Hasil & Keterangan \\
Sensor & $\begin{array}{l}\text { Sensor } \\
\text { Cahaya }\end{array}$ & Berhasil & \\
\hline MQ 135 Sensor & $\begin{array}{l}\text { Sensor } \\
\text { Kualitas } \\
\text { Udara }\end{array}$ & Berhasil & \\
\hline Flame Sensor & $\begin{array}{l}\text { Sensor Api } \\
\text { dan Infrared }\end{array}$ & Berhasil & \\
\hline Gas Sensor V13 & $\begin{array}{l}\text { Sensor } \\
\text { Pendeteksi }\end{array}$ & Berhasil & \\
Kebocoran & & \\
Gas & & \\
\hline $\begin{array}{l}\text { Magnet Reed } \\
\text { Switch }\end{array}$ & $\begin{array}{l}\text { Sensor } \\
\text { Pendeteksi } \\
\text { Pintu Terbuka }\end{array}$ & Berhasil & \\
\hline
\end{tabular}

\begin{tabular}{|l|l|l|l|}
\hline Detector Module & Gerakan & Berhasil & Tambahan \\
\hline IC DS18B20 & Sensor Suhu & Tidak & Memerlukan \\
One-Wire & & Berhasil & Library \\
Temperature & & & Tambahan \\
Sensor & & & \\
\hline
\end{tabular}

Berdasarkan Tabel 3 pada pengujian kompatibilitas sensor dapat ditarik kesimpulan bahwa beberapa sensor yang dipasang dapat berfungsi dengan baik. Sedangkan ada beberapa sensor seperti sensor pendeteksi gerakan dan suhu memerlukan library tambahan, sehingga sensor tersebut tidak dapat bekerja dengan baik.

\section{Pengujian Multi Pengguna}

Pengujian berikutnya adalah pengujian multi pengguna yang bertujuan untuk mengetahui apakah ada fungsi yang salah pada sistem ketika digunakan lebih dari satu perangkat.

Tabel 4

Tabel Pengujian Multi Pengguna

\begin{tabular}{|c|c|c|}
\hline Jenis Pengujian & $\begin{array}{l}\text { Hasil Yang } \\
\text { Diharapkan }\end{array}$ & Hasil \\
\hline $\begin{array}{l}\text { Mengirim perintah } \\
\text { "On" pada relay } 1 \mathrm{di} \\
\text { perangkat } 1\end{array}$ & $\begin{array}{l}\text { Relay } 1 \text { pada } \\
\text { perangkat } 1 \text { hidup }\end{array}$ & Berhasil \\
\hline $\begin{array}{l}\text { Mengirim perintah } \\
\text { “On" pada relay } 1 \mathrm{di} \\
\text { perangkat } 2\end{array}$ & $\begin{array}{l}\text { Relay } 1 \text { pada } \\
\text { perangkat } 2 \text { hidup }\end{array}$ & Berhasil \\
\hline $\begin{array}{l}\text { Mengirim perintah } \\
\text { “On" pada relay } 2 \mathrm{di} \\
\text { perangkat } 1\end{array}$ & $\begin{array}{l}\text { Relay } 2 \text { pada } \\
\text { perangkat } 1 \text { hidup }\end{array}$ & Berhasil \\
\hline $\begin{array}{l}\text { Mengirim perintah } \\
\text { “On" pada relay } 2 \mathrm{di} \\
\text { perangkat } 2\end{array}$ & $\begin{array}{l}\text { Relay } 2 \text { pada } \\
\text { perangkat } 2 \text { hidup }\end{array}$ & Berhasil \\
\hline $\begin{array}{l}\text { Mengirim perintah } \\
\text { “Off” pada relay } 1 \mathrm{di} \\
\text { perangkat } 1\end{array}$ & $\begin{array}{l}\text { Relay } 1 \text { pada } \\
\text { perangkat } 1 \text { Mati }\end{array}$ & Berhasil \\
\hline $\begin{array}{l}\text { Mengirim perintah } \\
\text { “Off” pada relay } 1 \mathrm{di} \\
\text { perangkat } 2\end{array}$ & $\begin{array}{l}\text { Relay } 1 \text { pada } \\
\text { perangkat } 2 \text { Mati }\end{array}$ & Berhasil \\
\hline $\begin{array}{l}\text { Mengirim perintah } \\
\text { “Off” pada relay } 2 \text { di } \\
\text { perangkat } 1\end{array}$ & $\begin{array}{l}\text { Relay } 2 \text { pada } \\
\text { perangkat } 1 \text { Mati }\end{array}$ & Berhasil \\
\hline
\end{tabular}




\begin{tabular}{|l|l|l|}
\hline $\begin{array}{l}\text { Mengirim perintah } \\
\text { “Off” pada relay 2 di } \\
\text { perangkat 2 }\end{array}$ & $\begin{array}{l}\text { Relay 2 pada } \\
\text { perangkat 2 Mati }\end{array}$ & Berhasil \\
& & \\
\hline
\end{tabular}

Berdasarkan Tabel 4 pada pengujian multi pengguna dapat ditarik kesimpulan bahwa sistem yang dibangun sudah dapat mengirimkan dan menerima perintah sesuai dengan perintah yang dikirimkan ke masing-masing perangkat.

\section{Pengujian Kompatibilitas Aplikasi Terhadap Browser}

Tabel 5

Tabel Pengujian Kompatibilitas Aplikasi Terhadap Browser

\begin{tabular}{|c|c|c|c|}
\hline Nama Browser & Versi & Hasil & Keterangan \\
\hline Google Chrome & 45.0 .2454 .85 & Berhasil & \\
\hline Mozilla Firefox & 39.0 & Berhasil & $\begin{array}{l}\text { Beberapa } \\
\text { pengaturan CSS } \\
\text { tidak tampil } \\
\text { maksimal }\end{array}$ \\
\hline Internet Explore & $\begin{array}{l}8.0 .7601 .1751 \\
4\end{array}$ & Berhasil & $\begin{array}{l}\text { Beberapa } \\
\text { pengaturan CSS } \\
\text { tidak tampil } \\
\text { maksimal }\end{array}$ \\
\hline Opera Browser & 31.0 .1889 .174 & Berhasil & $\begin{array}{l}\text { Beberapa } \\
\text { pengaturan CSS } \\
\text { tidak tampil } \\
\text { maksimal }\end{array}$ \\
\hline
\end{tabular}

Berdasarkan Tabel 5 terlihat bahwa pengujian kompatibilitas aplikasi terhadap browser menghasilkan kesimpulan aplikasi dapat bekerja dengan baik pada setiap browser yang diujikan. Namun pada beberapa browser tampilan kurang maksimal karena kurangnya dukungan browser terhadap CSS yang digunakan.

\section{E. Analisis Hasil Pengujian}

Dari pengujian yang telah dilakukan, adapaun hasil analisis yang didapat dari Sistem Kontrol Listrik dan Monitoring Rumah adalah sebagai berikut:

1. Pengguna dapat melakukan kontrol listrik dan monitoring melalui aplikasi berbasis web.

2. Jumlah maksimal relay yang dapat dikontrol 8 buah, sedangkan maksimal sensor yang dapat pakai sebanyak 4 buah.

3. Kontrol relay dilakukan dengan cara memberikan perintah kepada IP mikrokontroler.

4. Perangkat hanya mampu menerima perintah secara beruntun sebanyak 5 kali karena terjadi delay pada sistem yang dibangun.
5. Pada monitoring sensor pengguna bisa melakukan kalibrasi pada aplikasi tanpa harus mengubah coding pada perangkat Arduino.

6. Sistem yang dibuat sudah mampu mengeksekusi 3 perintah yang dilakukan oleh 3 pengguna secara bersama-sama.

7. Beberapa jenis sensor tidak bisa berfungsi karena harus menambahkan komponen tambahan berupa library pada coding Arduino.

8. Sistem yang dibuat sudah mendukung multi pengguna.

9. Sistem yang dibuat sudah didukung interface sebagai antarmuka pengguna.

10. Sistem sudah didukung basis data sehingga dapat memberikan informasi kepada pengguna status terakhir listrik apakah dalam keadaan mati atau hidup.

11. Sistem yang dibangun tidak memerlukan perangkat tambahan seperti komputer, telepon genggam, dll. Cukup menggunakan jaringan internet yang umumnya sudah tersedia dirumah pengguna tanpa perangkat tambahan lainnya.

12. Selain kontrol listrik, sistem sudah mendukung fungsi monitoring yang pengguna dapat gunakan untuk mengukur suatu kondisi.

\section{KESIMPULAN}

Setelah melakukan pengujian serta analisa terhadap Sistem Kontrol Listrik dan Monitoring Rumah, maka dapat ditarik kesimpulan sebagai berikut:

1. Pada sistem yang dibangun sudah diimplementasikan mikrokontroler untuk melakukan kontrol listrik dan monitoring rumah.

2. Sistem dapat melakukan kontrol listrik dan monitoring dengan maksimal relay yang dapat digunakan sebanyak 8 buah, serta sensor yang dimonitoring sebanyak 4 buah.

3. Sistem yang dibangun sudah mendukung multi pengguna.

4. Sistem yang dibangun sudah didukung interface sebagai antarmuka pengguna dan basis data sebagai media penyimpanan data monitoring yang dapat diakses pengguna kapan pun.

5. Sistem yang dibangun sudah mampu melakukan kalibrasi terhadap sensor tanpa harus membuat perubahan terhadap struktur pemrograman yang sudah dibangun.

6. Untuk beberapa jenis sensor diperlukan tambahan library pada struktur pemrograman agar dapat bekerja dengan baik.

\section{DAFTAR PUSTAKA}

[1] Lazuardi, Arya. 2008. Perancangan dan Sistem Pengendalian Switch Breaker Pada Jaringan Listrik Dengan Menggunakan Remote Control Via SMS. Skripsi Sarjana Pada Universitas Indonesia. Tidak Dipublikasikan. Sumber: http://lib.ui.ac.id/opac/ themes/green/detail.jsp?id=124506\&lokasi=lokal

[2] Ichwan, Muhammad., Husada, Milda Gustiana., Rasyid, M. Iqbal Ar. 2013. Pembangunan Prototipe Sistem Pengendalian Peralatan Listrik Pada Platform Android. Jurnal Informatika. Vol. 4 (I). Hlm 13-25

[3] Iswanto. 2008. Belajar Mikrokontroler AT89S51 Dengan Bahasa C. Yogyakarta. C.V Andi Offset 